\title{
Análisis de los primeros conflictos obreros en la Patagonia Austral
}

Rosario Güenaga

Universidad Nacional del Sur y CONICET

Bahía Blanca, Argentina

Antes de las grandes huelgas patagónicas (1921-1922),en el territorio argentino de Santa Cruz, la relación entre los sectores patronales y obreros registra antecedentes de conflicto que deben entenderse dentro de un marco que incorpora no sólo la estructura socioeconómica sino también la influencia ideológica de los grupos actuantes. Los sectores de poder se mueven dentro de un contexto que incluye el dominio de las reglas de la sociedad, la cual, por sus características originarias y productivas, es terrateniente y latifundista. La reacción frente a la estructura vigente y las relaciones de trabajo surge de la agremiación de los trabajadores, primero en Magallanes y, poco después, en Santa Cruz. La primera en surgir, en el territorio austral argentino, fue la Federación Obrera de Río Gallegos que nació el 13 de mayo de 1913, conformándose la primera Comisión Directiva. La misma estaba formada en parte por trabajadores extranjeros, particularmente españoles. La influencia chilena, que es muy importante en la vida sindical del territorio, se había manifestado ya con anterioridad, actuando en las estancias argentinas con intención de crear subsedes de la Federación de Magallanes en este territorio. Por otro lado un representante de la organización chilena había actuado en forma protagonista en el momento de la creación de la de Río Gallegos, estipulándose desde el acta de fundación la hermandad entre las dos instituciones y la comunidad de ideas. La ideología que predominó, desde un primer momento, en el accionar obrero fue fundamentalmente anarquista y socialista, particularmente la primera. En este trabajo se presentan las primeras huelgas y la acción de los trabajadores, analizando sus motivaciones y las reacciones que produjo por parte de los sectores patronales y el gobierno.

\section{Introducción}

A fines de la presidencia de Hipólito Yrigoyen y antes de las grandes huelgas patagónicas ocurridas en 1921-1922, la relación entre los sectores patronales y obreros ya muestra antecedentes de conflicto que se sitúan dentro de un marco que agrupa no sólo la estructura socioeconómica sino también la influencia ideológica de los grupos actuantes. Este concepto resulta válido, pues es importante tener en cuenta los procesos que conducen a determinadas eclosiones sociales, para lograr una adecuada comprensión de las mismas.

Los sectores de poder se mueven dentro de un contexto que incluye el dominio de las reglas de la sociedad, la cual, por sus características origi- 
narias y productivas, es básicamente terrateniente y latifundista. A ello se agrega la conformación, a través de uniones familiares, originadas en los matrimonios, o en la asociación de intereses económicos dentro del mismo grupo, de una élite que alcanza el control de las reglas de poder e influye sobre la autoridad política. La estructura se basa, fundamentalmente, en el dominio de la tierra, de la producción y de diferentes actividades económicas dentro de una explotación dirigida, básicamente, a la exportación, que depende para el sustento de las importaciones, procedentes del mismo país o del extranjero. El grupo pionero, fundacional dentro de este sistema, se constituye en la élite dominante cuya conducta se encuadra dentro de la mentalidad del liberalismo económico agroexportador de la oligarquía ganadera argentina de 1880, sin contar con su tradición y sus antecedentes históricos.

La élite santacruceña, conformada en gran parte por extranjeros, no posee antecedentes de "notabilidad", según la definición que se le da en el trabajo de Diana Balmori, Stuart F. Voss y Miles Wortman: Las alianzas de familias y la formación del país en América Latina, por ser la mayoría de ellos inmigrantes que se iniciaron con escaso capital y poblaron tierras vírgenes poniéndolas en producción, logrando en pocos años un marcado poder. Pero una vez alcanzado el dominio de los mejores espacios, bajo el sistema de la gran propiedad, su conducta socioeconómica no los diferencia demasiado de otros grupos "notables" similares de Argentina. Sus actividades, prioritariamente ganaderas, no les impiden moverse con habilidad para insertarse en otras áreas, imperando sus intereses en el comercio y/o en el transporte. Mantienen una actitud no conflictiva con los capitales extranjeros, ya sean los británicos, los chilenos o los norteamericanos -en este último caso en relación con los frigoríficos- sin que las disputas de intereses por los precios entre los ganaderos y las industrias de la carne provoquen rompimientos definitorios, salvo las normales luchas por prebendas grupales.

La mano de obra rural y urbana va creciendo a medida que también lo hacen las estancias, la producción y el desarrollo del comercio y los servicios en las ciudades. El avance de las estructuras económicas, el aumento demográfico y la definición en los roles de cada grupo social, que se iba perfilando, introduce al lejano territorio dentro de los conflictos sociales que vive la época en esos años, pero con la particularidad de las fuertes relaciones existentes, desde los primeros momentos entre el territorio de Santa Cruz, en Argentina y el de Magallanes, en Chile. La particularidad 
que en este caso se encuentra es que los distintos aspectos socioeconómicos, conforman una región supranacional y política que trasciende las limitaciones que imponían las diplomacias de los gobiernos centrales.

\section{La relación con Chile}

La historia del territorio de Santa Cruz, particularmente en sus primeras décadas no puede ser entendida en la totalidad de su realidad inmanente si no la relacionamos con Chile a través de Magallanes. Las vinculaciones existentes en los años de colonización y poblamiento nos hacen pensar que se creó entre el sur argentino y el chileno una región propia, desde el punto de vista socioeconómico, que entrelaza las dos historias.

En muchos casos el estudio de las regiones no puede limitarse a las líneas demarcatorias de las naciones o las provincias. Si tomáramos sólo este concepto veríamos un aspecto parcial de la realidad, nos quedaríamos meramente en el análisis de un proceso fraccionado, puntual, fáctico y a veces sin encontrar la explicación subyacente del porqué ocurre algo y qué consecuencias produce más allá de la ubicación y la temporalidad inmediata. Los intereses económicos y las relaciones sociales no siempre quedan circunscriptos a lo lugareño, muchas veces atraviesan fronteras políticas y crean nuevos espacios de acción produciendo una red de intereses intraterritoriales propios que no siempre tienen que estar vinculados con los proyectos nacionales, sino que responden a proyectos propios de sectores o grupos sociales, de acuerdo a sus necesidades particulares. Esto no significa que tengamos que pensar en la ausencia del Estado Nacional, el cual se manifiesta en las leyes, las instituciones, las autoridades y los proyectos oficiales de desarrollo económico y social, sino comprender que, desde el punto de vista de las historias no oficiales, existe un movimiento paralelo que, sin desconocer o desvirtuar las pautas impuestas por el orden nacional, desarrolla una vida propia en convivencia con las regiones vecinas, que muestra una cotidianeidad más cercana a la mutua influencia e interrelación con el territorio cercano que con la región central. Ésta, a pesar de dirigir el gobierno político y económico, en los hechos es parte del desarrollo de la vida interna de la provincia. Esta convivencia se dio particularmente cuando era Territorio Nacional, originando dos movimientos con dos direcciones influyentes sobre él, a veces contrapuestas y otras convergentes según los intereses en juego: el poder del orden nacional y los intereses regionales con Magallanes. 
Tales fuerzas son las que se mueven dentro de la historia de Santa Cruz: el gobierno nacional imponiendo su soberanía a través de las leyes, las instituciones y los proyectos oficiales, y las fuerzas individuales que conjugan su conducta dentro del orden político del país con la influencia y centripetismo que produce Magallanes, sobre todo durante la primera época, como foco de mayor desarrollo y fuerza económica y expandiéndose en distintos aspectos sobre una zona menos desarrollada.

Los dos territorios, el chileno y el argentino, tienen algunas similitudes que las hacen comparables, aunque la humedad del Pacífico origina en Magallanes zonas de mayor verdor y fertilidad. Los límites políticos sirven para marcar la soberanía de las naciones, pero no interrumpen abruptamente, en la mayoría de los casos, las características del suelo y del clima en forma inmediata a las líneas divisorias. Las particularidades geográficas de los dos territorios dan origen, en las dos partes, al desarrollo de la producción ovina y a la existencia de grandes propiedades, que originará el surgimiento de sectores rurales de fuerte poder económico. Este aspecto común propiciará la extensión de capitales y producción desde Magallanes hacia Santa Cruz, tierra más deshabitada y con un desarrollo más tardío que el chileno.

La oportunidad de obtener tierras vírgenes, vacías de productividad, con características parecidas y que ofrezcan la posibilidad de prolongar en suelo argentino el desarrollo de la ganadería ovina, tal como lo hacían en Magallanes, propicia la aparición de capitales chilenos en el ámbito rural argentino. De ahí que, desde un principio, se cree una red de intereses económicos y posteriormente familiares entre los dos territorios, conformando, de hecho, una región socioeconómica que tendrá una gran fuerza. $\mathrm{Si}$ a esto le agregamos que con el desarrollo de la producción ganadera también se produjo una fuerte vinculación e intercambio de mano de obra de una zona a otra, las vinculaciones y relaciones se estrechan aún más.

Además era inevitable que así sucediera, porque frente a las características de frontera que presentaba Santa Cruz, donde convivían indios y blancos, con pequeños poblados y con mayoría de tierras improductivas, se alzaba Magallanes, comparativamente a su favor, con un desarrollo comercial, financiero, naviero y rural ya establecido y en franco crecimiento, lo que produjo un movimiento centrípeto en cuanto a la centralización de las actividades económicas de la región santacruceña, por proximidad e ineficiencia del gobierno argentino en esta materia, y a su vez centrífugo en lo referente a la ampliación del área económica hacia las tierras argentinas. 
Todas estas cuestiones deben explicarse para poder entender cómo a veces las historias de las provincias han de estudiarse a través de las relaciones que se establecen fuera de sus fronteras, dada la influencia que esos vínculos ejercen en el devenir histórico de ellas.

\section{Los extranjeros}

En otros trabajos ya he señalado la importancia del extranjero dentro del poblamiento del territorio. Los no nativos conformaron una mayoría activa que alcanzó un sobresaliente papel dentro de los distintos planos. Entre ellos los dos grupos más importantes en número fueron, primero los españoles y en segundo lugar los chilenos. Dentro de los primeros, la mayoría de ellos asturianos, muchos alcanzaron un fuerte poder económico y social, que los convirtió en parte de la élite originaria de la región. Todavía en el censo de 1947 el predominio de extranjeros no decrece a pesar del aumento de argentinos. ${ }^{1}$

Así como era mayoría el número de extranjeros dentro del grupo de los propietarios, también lo era en el de los trabajadores asalariados. Esta situación está vinculada con el desarrollo del sindicalismo en Santa Cruz. Se destacan los dos grupos mayoritarios - españoles y chilenos- con algunas diferencias en su actividad. Los primeros, no sólo ejercitan la práctica activa sino que también dan un fuerte contenido ideológico a la lucha por sus derechos; los segundos mantienen una presencia más activa y directa, aunque quizá, con menos aporte teórico — por lo menos en el número de cabezas visibles- que los españoles.

1 Para obtener mayores referencias sobre esta cuestión se sugiere ver: Güenaga, Rosario: "Aportes para la historia social de la Patagonia Austral”, Revista Karu-Kinka, número 28, Buenos Aires, 1981, págs. 113-124; "La presencia alemana en el extremo austral de América", Jahrbuch fur Geschichte von Staat, Wirtschaft und Gesellschaft Lateinamerikas, Colonia, Alemania, 1989, páginas 201-227; "Los españoles en Patagonia", publicado en Inmigración española en la Argentina, (Seminario 1990), Oficina Cultural de la Embajada de España, Buenos Aires, 1991, págs 160-172; "La conformación social en un territorio de inmigración", Estudios Latinoamericanos, SOLAR, Santiago, Chile, 1991, págs. 54-60; Santa Cruz y Magallanes. Historia socio-económica de los territorios de la Patagonia Austral argentina y chilena. (1843-1925), Instituto Panamericano de Geografía e Historia, 1994; Los extranjeros en la conformación de la élite santacruceña, Bahía Blanca, Departamento de Humanidades, Universidad Nacional del Sur, 1994; "El sector trabajador santacruceño entre fines del siglo XIX y principios del XX", Estudios socioeconómicos del sur argentino N. ${ }^{\circ} 1$, Departamento de Humanidades, Universidad Nacional del Sur, 1995, págs. 101-120. 
Por lo tanto, el significativo número de extranjeros dentro del sector laboral estará íntimamente vinculado al desarrollo de la vida sindical santacruceña, con marcada influencia ideológica de los mismos, que arrastran su anterior experiencia y formación de sus naciones de origen.

Si dedicamos nuestra atención a la mano de obra dependiente de las distintas actividades, inmediatamente surge el predominio de españoles y chilenos, seguidos por otras nacionalidades como rusos, polacos, etc.

\section{Surgimiento del movimiento obrero en Santa Cruz}

La Federación Obrera de Río Gallegos (capital del Territorio y la primera agremiación obrera que surge) nace el 13 de mayo de 1913, conformándose la primera Comisión Directiva. La misma estaba integrada en gran parte por trabajadores extranjeros, particularmente españoles. La influencia chilena y su actividad se había manifestado ya con anterioridad, introduciéndose en las estancias argentinas con intención de crear subsedes de la Federación de Magallanes en territorio santacruceño. En el momento del surgimiento de la Federación Obrera de Río Gallegos un representante de la Federación chilena había actuado en forma protagónica en el momento de su creación, estipulándose desde el acta de fundación la hermandad entre las dos instituciones y la comunidad de ideas. La ideología que predominó, desde un primer momento, en la actividad obrera santacruceña fue fundamentalmente anarquista y socialista, destacándose la influencia de la primera.

\footnotetext{
"Durante el siglo XIX anarquistas y socialistas fueron las dos principales corrientes ideológicas animadoras del movimiento obrero. Hubo otras de menor peso, como los grupos católicos que actúan en los últimos años del siglo o los mazzinistas y republicanos italianos. Además, en muchos casos aparecen militantes sindicales que no pueden ser encasillados en ninguna de las dos grandes corrientes... Pero en general son los anarquistas y los socialistas los que desempeñan los papeles más importantes como impulsores del movimiento obrero". ${ }^{2}$
}

Sin que la intención de este trabajo sea desarrollar la evolución del movimiento obrero argentino diremos, brevemente, que ya a partir de la fundación de la Unión Tipográfica en 1878 se constituyen una serie de agrupaciones por actividad que hace que en 1895 sean veinticinco las aso-

2 Falcón, Ricardo: Los orígenes del movimiento obrero (1857-1899), Buenos Aires, 1984, pág. 92. 
ciaciones de orden gremial que encauzan la acción orientada a distintos reclamos, manifestándose a través de huelgas y diferentes tipos de protesta. Finalmente en 1891 se crea la Federación Obrera, que proclama la unión de todos los trabajadores en defensa de sus derechos y la modificación de las relaciones de trabajo entre los sectores obreros y patronales. Sin embargo, las dificultades de entendimiento entre distintas posturas políticas, fundamentalmente entre socialistas y anarquistas, llevan a la desaparición de la Federación Obrera Argentina.

Después de varios intentos rápidamente abortados, en 1901 aparece la cuarta Federación Obrera, que al año siguiente inicia la ruptura entre socialistas y anarquistas, quedándose éstos últimos con la dirección de la Federación, que en 1904 pasa a llamarse Federación Obrera Regional Argentina (FORA). Del fragmentarismo, producto del enfrentamiento ideológico, surge otra agrupación como la Unión General de Trabajadores (UGT), al principio orientada por los socialistas y en donde, al poco tiempo, comienza a manifestarse la orientación sindicalista que inicia conversaciones con la FORA, al expresarse esta última tendencia más cerca de los anarquistas de la FORA, sin que se llegara a realizar la unidad intentada en 1907. Fuera de la FORA, surge otra agrupación, la CORA, a costa de la desaparición de la UGT. ${ }^{3}$ A pesar de estos intentos de unificación, las diferencias ideológicas no permitirán la consolidación de la organización obrera. En 1914 se organiza un Congreso de Concentración Obrera, donde se reunieron representantes de la CORA y de la FORA. Un año después se realiza el IX Congreso de la FORA, en el cual se redacta un informe que se contradice con lo dispuesto en el V Congreso de la FORA, produciendo el alejamiento de los anarquistas y quedando el movimiento obrero separado en la FORA del V Congreso y la FORA del IX Congreso. ${ }^{4}$ Sin embargo, estas divisiones que se manifestaban en Buenos Aires no se hicieron presentes, en un primer momento, en el sur. El mismo escudo de la Federación de Río Gallegos no indicaba a qué línea pertenecían. Aunque el espíritu predominante, como se dijo anteriormente, fue el anarquista, no impide que en los primeros años de acción gremial se vislumbren fracturas internas.

Si la documentación existente nos demuestra la relación que hubo entre la política sindical argentina y la actividad política obrera de Santa Cruz, debemos hacer una brevísima mención de la situación en Chile. En

3 Resumen extraído de Panettieri, José: Los Trabajadores, Buenos Aires, 1968.

4 Rosa, José María: Historia Argentina, , Buenos Aires, 1976, tomo 9, págs. 274-275. 
el caso del sur patagónico es imposible dejar de lado la influencia del sindicalismo chileno sobre el santacruceño. A esta cuestión ya nos hemos referido en forma breve anteriormente, por lo que sólo repetiremos el concepto de que la agremiación santacruceña, desde el punto de vista pragmático y coyuntural, tenía más vinculación inmediata con la de Magallanes que con las del resto de Argentina. En Chile la actividad gremial y la lucha de los trabajadores tenía una antigüedad similar a la argentina, destacándose el enfrentamiento violento y la represión sangrienta registrada en las salitreras y en el puerto de Iquique. Con respecto a la organización obrera chilena se señala que:

\begin{abstract}
"Después de la represión de 1907, el movimiento mancomunal se va reorganizando lentamente, siempre con su centro de influencia en el Norte. En 1912 se funda en Iquique, el Partido Obrero Socialista, dirigido por Luis E. Recabarren, un antiguo tipógrafo. Este movimiento está íntimamente entrelazado con las mancomunales, que actúan como semilleros de sus líderes. Recabarren fue director de varios diarios y periódicos publicados por las mancomunales del Norte. Como resultado de su obra organizativa, se da la primera gran expresión organizada del sindicalismo chileno, a través de la Federación Obrera de Chile, que realiza un congreso en 1917. Esta entidad ya existía desde hacía unos años, como federación mutual. A partir de ese congreso, toma decisivo cariz sindical, iniciando una política militante y que consigue también adhesiones en Santiago y Valparaíso y de la zona de Concepción. En 1919, en un congreso realizado en Concepción, adopta como insignia la bandera roja, y dos años después adhiere a la Internacional Sindical con sede en Moscú". ${ }^{5}$
\end{abstract}

Como fácilmente se puede entender, la existencia de las organizaciones gremiales no constituye por sí misma un factor de conflicto. Para ello tienen que prevalecer condiciones socioeconómicas que alimenten las situaciones de crisis. Si avanzamos en la segunda década del siglo XX, en el territorio de Santa Cruz observaremos que aspectos tales como las dificultades para la adquisición de la tierra con la facilidad de los primeros tiempos y las condiciones de vida del trabajador santacruceño, ${ }^{6}$ unidos al ingrediente ideológico que incorporan los grupos trabajadores, particularmente los inmigrantes y la constitución de la organización gremial, constituyen elementos a tener en cuenta, en forma muy atenta, ante el surgimiento de las primeras manifestaciones de protesta de los obreros.

5 Di Tella, Torcuato S. y otros: Sindicato y Comunidad. Dos tipos de estructura sindical latinoamericana, Buenos Aires, 1967, pág. 51.

6 Güenaga, Rosario: "Condiciones de vida y trabajo del trabajador santacruceño", Noveno Congreso Nacional y Regional de Historia Argentina, Academia Nacional de la Historia, Buenos Aires, 1996. 
En cuanto a la relación patrón-obrero, Rouquié hace una interesante consideración de orden general con respecto a los trabajadores a principio de este siglo, pero que se compatibiliza con la situación en el extremo sur patagónico:

"Ante esas condiciones de vida que recuerdan las de Europa durante la revolución industrial, pero que existen cincuenta o cien años más tarde, la actitud de la patronal y las autoridades consiste en negar los problemas sociales y rechazar las reivindicaciones obreras, justificando el recurso de la violencia. Los asalariados deben mostrarse agradecidos con el patrón que les da trabajo, cuando tantos de sus semejantes buscan un puesto. En esos países todavía rurales, [en este caso no se trata del país, sino de la región que aún forma parte de las sociedades rurales] donde el empleo relativamente estable y pagado con dinero es escaso, el trabajo asalariado urbano puede parecer un privilegio. Los grupos dirigentes consideran que la lucha de clases no tiene cabida en el Nuevo Mundo, que es, como las ideologías obreras, una 'planta exótica' importada desde Europa corrupta y decadente. Todo intento de organización es aplastado por la fuerza. Se expulsa a los "agitadores" extranjeros, responsables de perturbar el clima idílico de las relaciones entre el capital y el trabajo. En 1904, el gobierno argentino promulga una llamada ley "de residencia", no abolida hasta 1958".?

Si analizamos la documentación del territorio desde principio del siglo $\mathrm{XX}$, referida a conflictos y ciertas situaciones de inseguridad, que se tramita ante las autoridades oficiales, encontramos el uso del término "bandolerismo" por parte de funcionarios y patrones para calificar la acción de algunos grupos que causaban preocupación a los sectores de poder. Pero ese empleo ambiguo de la palabra "bandoleros" debe ser tomado con cuidado, pues su uso indiscriminado puede producir confusión para distinguir a los delincuentes de los gremialistas. No debe mezclarse con la actividad posterior de los trabajadores agremiados, a quienes en los primeros momentos se les consideró o llamó delincuentes. La falta de personal policial y de seguridad para las estancias llevó, en repetidas oportunidades, a las autoridades locales a solicitar refuerzos de todo tipo al Ministerio del Interior:

"Como VE sabe estos departamentos [se refiere a Gallegos y Santa Cruz] por encontrarse limítrofes con Punta Arenas son el refugio obligado de todo cuanto individuo de mal vivir existe tanto en el Territorio Chileno como Argentino, viniendo a convertirse así en el azote de la campaña, lo que es motivo para que frecuentemente ocurran las estancias en demanda de auxilio, viéndose esta Gobernación obligada a hacer oídos sordos por la imposibilidad en que se halla de prestarles ninguna ayuda".

7 Ronquié, Alain: Extremo Occidente-Introducción a América Latina, Buenos Aires, 1990, págs. 156-157.

8 Archivo General de la Nación, Territorios nacionales, legajo 7, Buenos Aires, 1903. 
Los reclamos se repiten al año siguiente y sucesivamente en los distintos informes de la gobernación y de la policía. A tal punto llega la necesidad de seguridad dentro de los territorios australes que una comisión de vecinos de Chubut, Santa Cruz y Tierra del Fuego escribe una larga petición al Ministerio del Interior solicitando protección:

\begin{abstract}
"A los territorios del Sud afluyen todos los criminales que escapan o esquivan a la justicia de la Provincia de Buenos Aires, los que son expulsados de Chile y los que cumplida la condena o por otra causa salen del presidio de Ushuaia; el despoblado, la escasez de policía y la impunidad los incita a cometer nuevas fechorías...". 9
\end{abstract}

La petición incluía la conveniencia de crear el cargo de comisario adhonorem, nombrando para ello a algunos estancieros que dispusieran de la ayuda de agentes "bien armados y bien montados". Esta solicitud sorprendente, hubiera retrotraído a nuestro país, por lo menos en esa región, a la época de los ejércitos particulares de los caudillos rurales.

Aunque es necesario no dejar de lado estas cuestiones como elementos de análisis, hay que tener muy claro que no se debe confundir la actividad de los grupos delictivos con la acción de los sindicalistas. Vale esta aclaración, ya mencionada anteriormente pero que debe tenerse muy en cuenta, pues en varias oportunidades éstos últimos han sido denominados bandoleros por parte de distintas autoridades del territorio; y si bien en las distintas manifestaciones obreras se mezclaba diferente tipo de elementos que producían hechos confusos, los objetivos de la asociación de los trabajadores eran evidentemente otros.

Como dijimos, la actividad gremial institucionalizada en Santa Cruz comienza en 1913, pero previamente ya se había notado la presencia de agremiados de Magallanes con la intención de crear subsedes en territorio argentino. En 1913 el Ministerio del Interior solicita para interés del Departamento Nacional de Trabajo información sobre huelgas y accidentes de trabajo ocurridos en el territorio en 1912. La gobernación local contesta que no tiene conocimiento de ninguna de las dos circunstancias durante el año mencionado. Pero significativamente ese mismo año el mismo Ministerio le pide información sobre la existencia y características, en caso de que las haya, de Sociedades de Socorros Mutuos en la región. No encontramos otra documentación expresa que relacione las dos inquietudes del Ministerio del Interior, pero podría resultar materia de interés ver si existe

9 Ibídem, legajo 17, 1910. 
alguna relación entre las dos requisitorias del Ministerio, dado que en más de una oportunidad las Asociaciones de Socorros Mutuos fueron sede de actividades gremiales y políticas.

Ya en 1914 parecen encontrarse manifestaciones de algún contenido sectorial cuando el Ministerio requiere del director de Territorios Nacionales información sobre ciertos hechos denunciados por el comandante del transporte "1 de Mayo" al Ministerio de Marina. Según el texto del telegrama, de fecha del 22 de diciembre, el subprefecto y las autoridades terrestres daban por restablecido el orden y

"encuéntranse detenidos — dice— setenta y ocho individuos, mayoría agitadores y presuntos atacantes a la policía mano armada quienes están a disposición juez letrado, he dispuesto enviar un destacamento de diez hombres ... para reforzar personal subprefectura dado que la policía desarrolla su cometido en la campaña. Autoridades me piden sería necesario eliminar de la población elemento pernicioso que se me indicara. En consecuencia si UD. lo considerara conveniente podría dejarse el destacamento a cargo del subprefecto y conducir con el buque en oportunidad y al punto que UD. determine y los individuos mencionados que son en su totalidad extranjeros...". ${ }^{10}$

La información es confirmada por el gobernador, aclarando que la policía ha sido distribuida en las estancias y que los huelguistas están diseminados y buscando trabajo. Según el gobernador habría cuarenta agitadores detenidos, de quienes considera que: "Sería medida acertada expulsar de aquí o transportar en el buque agitadores y demás elementos perniciosos....". ${ }^{11}$

Durante el año de 1915 los conflictos comienzan a crecer. Ya a principios de año se señala la existencia de cuadrillas de peones camineros organizados como el año anterior. En previsión de nuevos conflictos la policía local solicita más refuerzos de municiones, dado que en la huelga del año pasado habían sufrido falta de ellas. En octubre vuelven a renacer los problemas, pidiéndose que se envíe "la primera comisión que se ofrezca" junto con el jefe de policía.

Nótese que los actos de descontento gremial surgen, generalmente, a fines de año, época en que comienza la esquila y el traslado de grupos humanos desde distintos países, particularmente desde Chile. Todavía algunos siguen confundiendo o mezclando a bandoleros con huelguistas, pues una comunicación desde San Julián al gobernador señala que

10 Archivo Histórico de Santa Cruz, leg. 134, Santa Cruz, 1914.

11 Ídem. 
"seguro de la preocupación e intereses de usía en tener detalles de los acontecimientos en este departamento que revisten, por cierto, mucha gravedad no se trata de ningún movimiento obrero puesto que no existe tal huelga, casi estoy en decir que es una verdadera sedición compuesta con todo elemento maleante calculando de cincuenta individuos divididos en pequeños grupos y diseminados para cometer toda clase de tropelías". ${ }^{2}$

Sin embargo, desde la estancia San José se comunica que se ha producido una huelga que tiene algunas características dignas de citar:

"El motivo de la huelga fue que los trabajadores habían recibido orden de la Federación Obrera de Punta Arenas (Chile) de parar el trabajo el día 1 lo que así se hizo; cuando llegué los trabajadores se fueron todos a Puerto Natales de donde regresaron el día 3 por la tarde y previa un acuerdo entre el Sr. Fernández y los trabajadores en presencia del suscripto [firma de un subcomisario]; la huelga quedó solucionada y en el día de ayer volvieron todos al trabajo; no se ha producido ninguna novedad, los huelguistas estuvieron sumamente tranquilos... Continuamente llegan delegados de la Federación de Obreros de Punta Arenas a las estancias en nuestro territorio y son siempre los promotores de las huelgas, no he podido todavía detener a ninguno por cuando llega a mi conocimiento ya han salido del Territorio". ${ }^{13}$

De hecho hubo trabajadores detenidos, porque una nota firmada por cinco obreros retenidos en la Comisaría de Río Gallegos solicitan ayuda económica, una vez recuperada su libertad, para retornar a San Julián.

Sin embargo, a principios de 1915 la situación no se tranquilizaba pues en un telegrama importantes estancieros de San Julián (todos ellos con apellidos de origen británico y alemán) piden a la Gobernación de Santa Cruz, con tono de alarma, lo siguiente:

"Los abajo firmados (sic) vecinos de ésta, pobladores con hacienda lanar viéndonos amenazados por instigadores al paro de trabajo si no se acude a pretensiones absurda por gente de propaganda huelguista, lo que puede traer graves consecuencias a nuestras vidas y haciendas por este elemento, en su mayoría de mal vivir, venimos ante su Excelencia a pedir garantías por cuanto la única en darlo sería la policía, pero ésta por más buena voluntad que tenga, el comisario con su personal tan reducidos que no pueden atender el auxilio que los pobladores soliciten en momentos de alteración de la tranquilidad en nuestros establecimientos por lo menos durante los meses de octubre y diciembre sería indispensable una policía volante al mando de un comisario por no tener medios rápidos de comunicaciones, la única que podrá auxiliarnos no obstante las grandes distancias que dista un punto u otras; hacemos también presente a SE que al no tomar medidas con tiempo nos veremos amenazados por este elemento pernicioso y comprometidos a afrontar cualquier situación..... ${ }^{14}$
12 Ibídem, leg. 145, 1915.
13 Ídem.
14 Ibídem. Leg. 137, 1915. 
Finalmente las autoridades del Territorio consideran fundadas las denuncias de una próxima agitación obrera en el Departamento de San Julián "pues en ese punto existe un grupo de deportados por infracciones a la Ley Social y otros elementos perturbadores...". ${ }^{15}$ La situación era doblemente peligrosa porque no sólo estaban amenazadas las estancias sino también el frigorífico y la fábrica de carnes que empleaban cuatrocientos hombres entre los meses de octubre y abril. A ellos había que agregar los trabajadores que llegaban para la esquila y que se distribuían en las estancias más poderosas. De ahí que, ante tantos temores, las autoridades consideraran la necesidad de tomar medidas de seguridad como la creación de partidas volantes a cargo de comisarios. La fuerza de contención podría estar reforzada por miembros de la gendarmería.

Frente a tales informes, también haciéndose eco de la situación, el Ministerio del Interior consideró convenientes las medidas propuestas.

\section{Síntesis}

El tema tiene continuidad, por los menos hasta que hacen eclosión los conflictos sectoriales con las grandes huelgas patagónicas de 1921-1922. Lo presentado tiene como intención mostrar, dentro de la brevedad del espacio, las fuerzas que comienzan a enfrentarse a partir de la organización gremial del territorio. Es un análisis básico de los principales elementos que encontramos en el inicio de la crisis de la estructura de trabajo en Santa Cruz. Éstos pueden ser resumidos, sin que por ello pretendamos agotar todos los factores ni queramos eliminar otros, en los siguientes aspectos:

1.- Una estructura latifundista, que crea una élite dirigente con pautas de conducta patriarcal.

2.- Una masa de mano de obra que arriba en una segunda oleada al Territorio y que no encuentra las mismas oportunidades que la primera para el desarrollo económico, dentro de un esquema de concentración de la tierra y el capital. La situación los limita a ocupar el lugar de asalariados o a dedicarse a actividades económicas más limitadas, dentro de una sociedad marcada por las reglas que impone la élite propietaria y usufructuaria predominantemente terrateniente.

15 Ídem. 
3.-Un proceso inmigratorio en el cual parte de sus miembros aportan su caudal ideológico y su experiencia como activistas en sus países de origen.

4.-Un desarrollo más o menos sistematizado dentro de la organización gremial, tanto en Argentina como en Chile.

5.-Una activa relación entre gremialistas santacruceños y magallánicos por identificación en la problemática laboral, ideológica y en muchos casos de origen, dentro de una macroestructura latifundista y ganadera común a las dos regiones.

Por lo tanto, considero válido e indispensable conocer los diversos factores que precedieron a las tan conocidas grandes huelgas de la Patagonia para entenderlas en su realidad, analizando sus antecedentes. 